\title{
El Archivo Histórico Judicial de la Ciudad de México
}

Carmen Saucedo Zarco

Universidad Nacional Autónoma de México y El Colegio de Michoacán, A. C.

En la ciudad de México está, entre otros archivos histórico-judiciales, el del Tribunal Superior de Justicia del Distrito Federal, que contiene documentación desde el siglo XVI hasta el siglo XIX, repositorio poco estudiado por los investigadores, a pesar de que en él existen ricos fondos que permiten conocer a la sociedad mexicana, tanto colonial como independiente.

Con el apoyo de El Colegio de Michoacán, se elaboró un Catálogo, que aunque abarca únicamente el período 1700-1730, es un acercamiento al contenido de este importante acervo, puesto que, a través de él, se muestra la actividad judicial de primera instancia, realizada por diversas autoridades como los alcaldes ordinarios, alcaldes mayores, corregidores, jueces de provincia, alcaldes del crimen, y en ocasiones, la Real Audiencia, así como otras jurisdicciones especiales.

El Archivo Histórico Judicial del Tribunal Superior de Justicia del Distrito Federal de México (en adelante AHJDF), puede ser para los investigadores, ya sean historiadores, antropólogos, sociólogos, juristas y demás interesados en las ciencias sociales, una rica fuente de información de la sociedad novohispana. Fundamentalmente permite conocer, desde otro punto de vista, la historia de México. Ha sido poco utilizado, debido al desconocimiento de la existencia de este repositorio, por las dificultades de su acceso y por las condiciones para su consulta, y también porque no se le ha concedido la importancia que merece como fuente para el estudio y análisis de la vida social y económica pasada.

Hace ya más de diez años, investigadoras norteamericanas hicieron pública su labor de "descubrimiento" y difusión de este Archivo, ${ }^{1}$ y a pesar del tiempo transcurrido, muy pocas personas se han acercado a él en busca de información.

1 Beardsley, Anne L., y Silvia M. Arrom: Mexico City's Tribunales and Penitencial Archives. New Sources for Mexican History "The Americas", XXXV, 2, Washington, Oct. 1978, págs. 249-252. 


\section{Archivos Judiciales en la Ciudad de México}

El principal repositorio documental que custodia expedientes sobre la impartición de justicia tanto en la época virreinal como en el siglo XIX, es el Archivo General de la Nación (México), y en sus diversos ramos puede consultarse principalmente lo relativo a la justicia extraordinaria y a la impartida en segunda instancia. ${ }^{2}$

Anne L. Beardsley y Silvia M. Arrom han descrito la documentación que trabajaron y vieron en el Archivo Judicial del Tribunal Superior de Justicia del Distrito Federal y en el Archivo General de los Juzgados Unitarios Penales, cuyos fondos contienen expedientes desde principios del siglo XIX. Este último Archivo ha sido objeto de nuestra búsqueda, hasta ahora infructuosa.

\section{Situación material y formal del AHJDF}

El AHJDF está ubicado en el sótano del edificio del Tribunal Superior de Justicia del Distrito Federal, en la calle de Niños Héroes, de la Ciudad de México.

La documentación no está expuesta al sol ni a fuentes directas de calor. Sin embargo, en tiempo de lluvias, las filtraciones de agua en el edificio han provocado que la humedad dañe severamente los documentos. No hay suficiente ventilación, lo que a la larga puede contribuir aún más a su deterioro. En términos generales, su estado de conservación, a pesar de las condiciones adversas, es bueno, aunque al abrir algunos legajos, se ha podido detectar expedientes danados parcialmente por el fuego y la polilla, mientras que otros muestran manchas de agua y hongos.

Los documentos están agrupados en legajos de cerca de trescientas hojas cada uno. Estos legajos contienen entre treinta y cinco y cuarenta expedientes, y se hallan apilados en anaqueles metálicos.

2 Archive General de la Nación. Guía (ieneral. México, 1990. 
El trabajo de consulta sólo puede hacerse en escasas dos mesas y con luz insuficiente, ya que no se ha contemplado la consulta pública de estos materiales, y tampoco se ha promovido un adecuado acondicionamiento para ello. Podemos atribuir esta situación, en parte, al poco espacio físico destinado a la parte histórica, que no ha sido considerada como una sección especial dentro del propio Archivo, sino integrante de él. Prueba de ello es que no ha recibido la denominación de "Archivo Histórico" como correspondería en este caso. Además de esto, el Archivo Judicial crece constantemente, reduciéndose los espacios y provocando que la documentación sature no sólo los anaqueles sino hasta los pasillos de tránsito. Además, es el propio investigador quien a su gusto toma el legajo que mejor le parezca, ya que los empleados se dedican sólo a atender la parte del Archivo en funciones. Por otra parte, el personal no tiene atribuciones de vigilancia, por lo que es fácil extraer cualquier documento. Por supuesto, estas circunstancias convierten al AHJDF en botín de coleccionistas pues es susceptible al saqueo.

\section{Documentación Colonial}

De la época de la dominación española se ha podido encontrar, entre la documentación más antigua, un documento del año de 1538; aunque los documentos correspondientes al siglo XVI son escasos, sumando sólo dos legajos. En cuanto al siglo XVII, hay aproximadamente sesenta legajos, que miden unos cinco metros lineales. Del siglo XVIII existen ciento cuarenta y cuatro legajos, distribuidos en quince y medio metros. A partir del año de 1780, los documentos se hallan divididos en asuntos penales y civiles, conservando las anteriores características de orden.

La documentación colonial está agrupada en legajos ordenados cronológicamente; cada legajo, que está atado con un cordón, tiene una etiqueta de cartón donde se consignan las fechas extremas de cada paquete. Examinando el interior de éstos, se observa que no siempre corresponden las fechas a las indicadas en la etiqueta. Además, en ésta se ha incluido una numeración progresiva. 
En el estudio titulado La Justicia en la Nueva España, que trata de formular una teoría sobre este importante tema, y que aparece en el Catálogo que hemos publicado, Jaime del Arenal Fenochio explica de la siguiente manera el contenido de la documentación colonial que guarda en el AHJDF:

"904 expedientes fueron catalogados dentro del proyecto de recuperación y salvamento del Archivo Histórico Judicial del Tribunal Superior de Justicia del Distrito Federal (AHJDF) emprendido por El Colegio de Michoacán, los cuales contienen una rica documentación relacionada con negocios, asuntos y litigios que determinaron el funcionamiento del aparato judicial de la ciudad de México durante los años de 1700 a 1730 , aunque también se catalogaron expedientes provenientes del corregimiento de Coyoacán, de la $\mathrm{Al}$ caldía Mayor de Xochimilco, y, en mínima parte, de otras jurisdicciones más o menos cercanas a la capital del virreinato. Para administrar la justicia ordinaria en dicha ciudad durante el período estudiado concurrieron tres instituciones cuya documentación es la que en forma mayoritaria guarda el AHJDF en su sección novohispana: el Juzgado de Provincia, a cargo de los alcaldes de la Sala del Crimen de la Real Audiencia de México, el corregidor de la ciudad capital de la Nueva España y los alcaldes ordinarios de ésta misma. El material catalogado - tanto el proveniente de la ciudad como de las otras jurisdicciones- en su mayor parte se relaciona con asuntos civiles, y cuando se encontró algún expediente relativo a la materia penal trata de lo que hoy conocemos como delitos contra la propiedad (robo, abigeato, despojo, abuso de confianza). No se encontraron, por el contrario, expedientes de causas criminales por delitos contra la vida, por delitos sexuales o de otro tipo, salvo, y sólo en contadas ocasiones, por injurias, lesiones, o calumnias. En síntesis, son expedientes de juicios o asuntos civiles, tramitados por vía de jurisdicción ordinaria - a excepción de algunos-, en primera instancia y, en su inmensa mayoría, tramitados dentro de las jurisdicciones territoriales de la ciudad de México, de Coyoacán y de Xochimilco. El grueso de los expedientes criminales del período, así como las apelaciones civiles o criminales, se conservan en otra parte del propio AHJDF y en los ramos Criminal, Civil y Real Au- 
diencia del Archivo General de la Nación (AGN) dado que las apelaciones eran de la competencia de dicho tribunal".

\section{Documentación del México Independiente}

El AHJDF guarda un gran acervo correspondiente a esta época. Así, hay mil ochocientos cincuenta y ocho legajos, en ciento noventa metros. En virtud de que el trabajo de catalogación se ha enfocado preponderantemente a la parte colonial, no ha sido posible identificar aún la fecha extrema que alcanzan los procesos contenidos en los documentos, pero se ha visto que rebasan al año de 1890. En lo que respecta a la documentación del México Independiente, ésta se halla clasificada por un orden alfabético tanto onomástico como temático, siendo éste último de criterio arbitrario. El orden alfabético se ha considerado que se basa en el apellido del demandado, pero se comprueba que no siempre es así, puesto que en ocasiones aparece clasificado por el apellido del actor. En la ordenación temática, a veces se consideraron los asuntos conforme a su determinación jurídica y legal estricta, pero en otras ocasiones, el clasificador, seguramente ignorante de la terminología jurídica, acomodó los expedientes atendiendo al objeto material sobre el cual versaba la controversia.

Por ejemplo, existen clasificaciones que responden a voces legales precisas, como sucesiones testamentarias, divorcios, homicidios, etc., pero también equivalencias arbitrarias como herencias, ganado, albercas, etc. A pesar de estas deficiencias, es posible consultar el Archivo con buen éxito. Las personas que clasificaron este material, consideraron importantes aquellos expedientes referentes a las sucesiones testamentarias, homicidios, lesiones, e injurias, por lo que de manera separada ordenaron también alfabéticamente por apellidos estos expedientes. Este orden le fue dado, posiblemente, hace unos treinta años.

Al igual que la documentación de la época virreinal, este período se distingue por contener los expedientes relativos a los juicios en primera instancia tanto civiles como criminales, que se 
tramitaron en la ciudad de México y algunas de las municipalidades que formaban el Distrito Federal, como San Angel y Tlalpan.

\section{Nuestro trabajo de Catalogación}

Orgánicamente, el Archivo Judicial del Tribunal Superior de Justicia del Distrito Federal, depende directamente de la Presidencia del Tribunal, teniendo un director a quien compete otorgar las autorizaciones para la consulta del Archivo Histórico.

Actualmente, y por la insistencia de quienes hemos realizado este primer intento de catalogación, ante los notorios saqueos de que ha sido víctima este Archivo, diversas instituciones se interesaron en su rescate y conservación, tales como El Colegio de Michoacán, el Instituto José María Luis Mora, y el Archivo General de la Nación, quienes están buscando la anuencia de la Presidencia del Tribunal, para trasladar los fondos del AHJDF a un sitio más adecuado, en caso de que el Tribunal no cuente con el espacio necesario.

Por esta razón, se ha considerado conveniente y urgente la elaboración de los instrumentos de consulta que permitan al investigador acceder a estos fondos, cuyo aprovechamiento, sin duda alguna, aportará mayores elementos para la historiografía mexicana y particularmente a la historiografía jurídica.

Atendiendo a esta necesidad se procedió a la elaboración de un catálogo - modesto ya que sólo se ocupa de los primeros treinta años del siglo XVIII - para, en primer lugar, conocer la clase de documentos que integran este archivo y en segundo lugar como modelo para continuar en el futuro esta ardua labor. ${ }^{3}$ Este trabajo pretende proporcionar al investigador, la información necesaria de manera sencilla y breve con el apoyo de útiles índices.

La ficha catalográfica ha sido diseñada de acuerdo a las características propias de esta documentación. En primer lugar aparece el nombre de la autoridad encargada de la impartición de justicia, su

3 Arenal Fenochio, Jaime del; Saucedo Zarco, Carmen; Ramírez Rodríguez, Salvador: Catálogo del Archivo Histórico Judicial del Distrito Federal. 1700-1730. Fichas 1-904. Zamora, El Colegio de Michoacán, en prensa. 
cargo (corregidores, alcaldes mayores, alcaldes del crimen y jueces de provincia, por ejemplo) y el lugar donde se lleva a cabo el juicio, y para complementar la información se han registrado otros lugares referidos en el expediente.

Las fechas señaladas corresponden a las extremas de cada proceso judicial y en algunos casos se ha consignado la correspondiente a otros documentos anexos o probatorios. En el resumen que se refiere al asunto del expediente, se han puesto en orden los nombres del actor y el demandado, así como el objeto del juicio, incluyendo cuando es necesario el nombre de otras poblaciones, o de haciendas y de conventos u otras corporaciones partícipes en el pleito judicial. Después, entre corchetes se ha anotado alguna observación relativa al estado de conservación del documento o su integración, o en su caso, sobre el papel usado cuando es distinto al sellado de costumbre.

Finalmente, después de la cantidad de hojas que integra el expediente, se ha puesto la ubicación topográfica, con su número de legajo (el original), y el número de expediente que le hemos asignado y cuyo número está escrito con lápiz en la portadilla.

Cada ficha catalográfica cuenta con un número progresivo para ser localizada fácilmente a través de los índices, de los cuales se han elaborado siete: de autoridades judiciales; de personas o corporaciones; de lugares; de asuntos; de escribanos; de documentos gráficos y de documentos en lengua mexicana. Estos últimos los hemos englobado con este término ya que, ignorantes de estas lenguas, no hemos sabido precisar si todos ellos están escritos en náhuatl u otro idioma hablado en la zona de la ciudad de México.

El índice de "justicias" o de autoridades judiciales se ha clasificado conforme a las distintas instancias que impartían justicia, por lo que es posible ver la conformación de la burocracia judicial, así como el ascenso o "desaparición" de algunos individuos a través de los diversos estratos de los muchos órganos de este gran aparato que aplicaba la multitudinaria legislación indiana. Es por ello que puede considerarse como el índice más importante, ya que su clasificación implicó el análisis de todas aquellas múltiples instancias que convivían en la Nueva España. 
Nuestro trabajo sólo ha podido abarcar una mínima parte de lo que constituye al AHJDF. Tan sólo 20 legajos, que ocupan los años de 1700 a 1730, han sido catalogados en 904 fichas, con lo cual al tiempo de aportar este instrumento de consulta, hemos querido también hacer una proposición del catálogo más adecuado, así como el estudio de esas instituciones jurídicas, hoy poco estudiadas.

Este Catálogo pudo hacerse gracias al patrocinio de El Colegio de Michoacán A.C., dirigido en aquel tiempo por el doctor Andrés Lira y por el maestro Carlos Herrejón, quienes encomendaron al licenciado Jaime del Arenal Fenochio, a Salvador Ramírez Rodríguez y a quien esto escribe, la tarea de llevarlo a cabo. El interés de todos nosotros ha sido la divulgación de este repositorio, que creemos es indispensable para el conocimiento de la historia novohispana. 